The ease of reversing the polymerization reaction supports the thesis that the primary biological role of RNA may be that of a source of readily available high-energy polyphosphate mononucleotides. The enzyme preparation displays a very strong phosphorylase activity toward the nucleic acid of the bacterium.

This investigation was supported by Research Grant C-2550 from the National Cancer Institute, National Institutes of Health, U.S. Public Health Service. I wish to acknowledge the technical assistance of Mrs. G. Olson in this study and the generous co-operation of the following persons who carried out the work on the polymer: $\mathbf{X}$-ray diffraction studies were under the supervision of Dr. R. S. Bear with Dr. R. S. Morgan; ultracentrifugation studies were made by Dr. D. A. Yphantis; electron microscopy studies were under the supervision of Dr. C. E. Hall; and the light-scattering measurements were made by Dr. R. F. Steiner.

ROLAND F. BeERS, JUN.

Division of Biochemistry,

Department of Biology,

Massachusetts Institute of Technology,

Cambridge 39, Mass.

1 Grunberg-Manago, M., and Ochoa, S., J. Amer. Chem. Soc., 77, 3165 (1955).

${ }^{2}$ Grunberg-Manago, M., Ortiz, P. J., and Ochoa, S., Science, 122, 007 (1955).

\section{Effect of Pinealectomy on the Rat Pituitary}

Pinealectomy in rats has been variously reported as resulting in no change ${ }^{1}$ or as causing a hypertrophy of the pituitary, with an increase in the proportion of acidophils of the anterior lobe, and some degenera. tion of the basophils2.

Blind subdural pinealectomy has been attempted on a small series of young male rats, aged two to four months. Those surviving the operation were killed six to twelve weeks afterwards. Histological examination of the brain confirmed that in eight animals the pineal body had been totally removed, whereas in the remaining seven it was still in its normal position, and apparently undamaged. The pituitary bodies of these two series of animals were fixed in Zenker-formol, sectioned and stained by Pearse's method ${ }^{3}$. Modified Rasmussen ${ }^{4}$ cell counts of the anterior lobes were then made, approximately five thousand cells being counted in each gland. The results are shown in Table 1.

These figures show that there is no significant difference between the cellular constitution of the anterior lobe of the pituitary of pinealectomized and non-pinealectomized animals. Successful removal of the pineal did not give rise either to a marked increase in the numbers of acidophils or to basophil degeneration. Colloid formation and development

Table 1

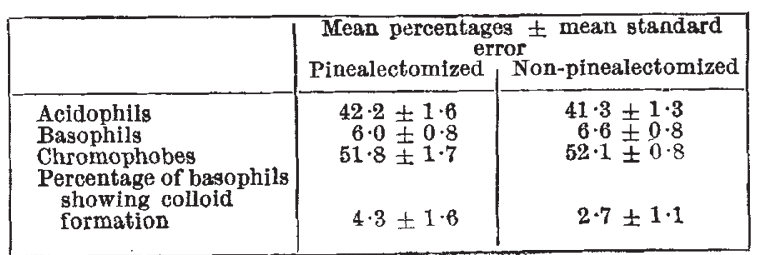

of 'signet ring' forms in the basophils were not significantly increased.

These findings indicate that the pineal body has no effect on the anterior lobe of the pituitary of the young male rat, and suggest that if gonadal changes such as have been reported ${ }^{5}$ do occur, they are not mediated via the pituitary.

\section{R. L. Hormes}

Department of Anatomy, School of Modicine, Leeds 2.

${ }^{1}$ Anderson, D. H., and Wolf, A., J. Physiol., 81, 49 (1934). a Ikuta, H., Acta Soc. Path. Jap., 28, 420 (1938).

${ }^{3}$ Pearse, A. G. E., Stain Tech., 25, 95 (1950).

- Rasmussen, A. T., Proc. Soc. Exp. Biol. N.Y., 19, 416 (1922).

simonnet, H., and Thiéblot, L., J. Physiol., 42, 728 (1950).

\section{Incomplete Wound Contracture and the Phenomenon of Hair Neogenesis in Rabbits' Skin}

Is rabbits, the healing of extensive wounds produced by excision of the full thickness of the skin of the trunk is the outcome of two distinct, though to some extent overlapping, processes which provide in turn a temporary and a definitive repair ${ }^{1}$. During the course of the first week or two, the defect becomes filled with granulation tissue, which is progressively epithelialized by the migratory ingrowth of epithelium from the wound margins. Closure of the raw tissue surface in this manner marks the completion of temporary repair. The definitive repair is brought about by contracture, a forced inward movement of the wound margins as a consequence of tensile forces generated within the substance of the granula. tion tissue or its derivatives ${ }^{2}$. Contracture, so it has been shown, is accompanied by a compensatory expansion of the integument surrounding the wound through intercalary or intussusceptive growth ${ }^{1}$.

Recent experiments by Billingham and Russell ${ }^{8}$ have shown that the process of contracture in experi. mental full-thickness wounds, ranging in area from about $10 \mathrm{~cm} . .^{2}$ to $50 \mathrm{~cm} .^{2}$ and of various shapes, including rectangles and circles, proceeds at a constant specific rate; that is, obeys the exact opposite of the familiar compound interest law of growth. The logarithm of the area of a wound decreases linearly with time, at least until the wound is not more than a few square centimetres in extent. The actual values of the specific rates of contracture fell within the range $5-8$ per cent of the wound area per day. In one series of extensive wounds, $20-40 \mathrm{~cm}^{2}$ in area, produced by excision of the full thickness of the skin down to, but not through, the panniculus on the trunks of thirty-two full-grown rabbits, contracture approached its theoretical end-point so closely in nineteen (that is, about 60 per cent) that only a narrow linear scar remained. In these animals the re-apposition of the skin of the original wound margins was virtually complete. In the remaining thirteen animals, however, the process of contracture terminated abruptly after the areas of their wounds had been reduced to about $5 \mathrm{~cm}^{2}$ or less.

Incomplete wound contracture was also observed in a further group of seven animals, of which three had been adrenalectomized before the excision of their cutaneous wounds, and four received daily administrations of $10 \mathrm{mgm}$. of cortisone acetate, 